\title{
Comparison of leadership style of male and female managers in Kuwait: An empirical investigation
}

\author{
Mitra Arami \\ Arab Open University (AOU), Kuwait branch, Ardiya, Kuwait
}

\begin{abstract}
2015 Research Leap/Inovatus Services Ltd. All rights reserved.

Keywords:

Leadership

Gender

Kuwait

Leadership style

Transformational leadership

MLQ

Several studies have investigated differences in leadership styles between male and female leaders. This paper analyzes weather Kuwaiti male and female leaders differ in their leadership behavior. Explorative approach is applied for this research study. This study is based on a small sample in Kuwait and based on a self-rating of managers in Kuwait. In our study, we used similar approach as Eagly and Johannesen-Schmidt (2001) - rating was done through subordinates, peers and superiors - this would help to have more in-depth analyses. The quantitative analysis involves 62 leaders ( 38 male, 24 female) from different industries in private and governmental sector in Kuwait. Results indicated no major differences in leadership behavior by gender in Kuwait, which is similar to outcome of some studies conducted in western countries. It should be highlighted that the percentage of male and female respondents varied between different organizations. Future research should emphasis on equal sampling. It would be also interesting to analyze the difference in male or female dominated industries. This study offers knowledge for developing leadership skills in Kuwait. Very few studies have concentrated on difference in leadership styles outside Europe and North America, this study provides a new perspective in a different cultural context.
\end{abstract}

\section{Introduction}

Some empirical investigations have been conducted on male and female leadership styles and how female leaders cope with being a leader (Eagly et al., 2003; Swim's, 1994: Hall and Carter's,1999; Eagly and Carli, 2007). Some other researchers have investigated the decision making process of male and female managers and found out that there is no difference between these groups (Essers and Benschopp, 2007).

Form a business perspective, it is difficult to determine if there is a difference of gender in leadership and if male and female have different leadership styles. Although there are many studies contributing to this field, we still know little about impact of gender on leadership styles. Furthermore, most studies have been conducted in Europe and North America. Therefore, the main question is, if this can be generalized to other cultures (Javidan and Dale, 2005). There is a gap in empirical investigations on this topic in Middle East, especially in Kuwait.

In line with reviewed literature, the main aim of this study is the investigation of gender impact on leadership style and explaining the difference of male and female leadership behaviors in Kuwait. This analysis is relevant not only for scientists, but also for practitioners, as there is still a gap in empirical investigations supporting theoretical clarity on the effect of gender on leadership behavior outside developed countries.

\section{Literature Review}

Lewin introduced different leadership styles: autocratic, democratic and laissez-faire (Lewin, 10239), which is the base of leadership theories. According to outcomes of several research projects, male qualify as better leaders in terms of performance (Schein, 2007: Essers and Benschopp, 2007). Other studies indicate that male leadership style is the most effective approach (Cooper et al., 1994; Alsos et al. , 2006; Fairlie and Robb, 2009).

Another approach is the full range leadership theory (Avolio and Bass, 1991). In this approach, three typologies of leadership behavior are presented: transformational, transactional and laissez faire. The nine distinct factors are defined as five transformational, three transactional and one laissez faire. Transformational factors are inspirational motivation, charisma, idealized influence attributed, idealized influence behavior, intellectual stimulation and individual consideration measures. Transactional factor are contingent reward, management-byexpectation active and management-by-expectation passive. Transformational and transactional leadership are viewed by different authors as either competing or complementary and according to outcomes of some studies, transactional style is less effective than transformational style (Benjamin, 2006) and transformational style is positively correlated to performance of organizations. 
According to Eagly et al., (2003),"the possibility that women and men differ in their typical leadership behavior is important because leaders' own behavior is a major determinant of their effectiveness and chances for advancement" (p. 569)

A number of authors (e.g. Eagly and Carli, 2007; Grisoni and Beeby, 2007; Eagly and Sczesny, 2009; Melero, 2011) have investigated different leadership characteristics based on gender. The finding is that female leadership is interpersonally oriented, whereas male have a task-oriented approach.

Task-oriented leadership is related to authority, hierarchy and achieving goals, whereas interpersonal leadership style is based on empowerment and motivation (Grisoni and Beeby, 2007; Melero, 2011).

Other researchers have categorized leadership style as autocratic and laissez-faire and argued that men have an autocratic leadership style, which is characterized as a strategic style and more decision making oriented, and female tend to prefer a participative decision making style (Bird and Brush,2002; Eagly and Johnson, 1990).

Bardasi et al. (2011) stated that men and female leaders employ different approaches in leading a business. Findings of Gaskill et al. (1996) was that male and female leaders apply different market strategies. Female leaders prefer a slow growth of the business, however, male leaders focus on growth strategies (Kepler and Shane, 2007; Zolin and Watson, 2012).

According to outcome of other research studies, female leaders focus more on stable employment and responsibility for employees (Danes et al. , 2007), and also a long-term client relationships (Krishnan and Park, 2005; Schaap et al. , 2008), and some studies therefore suggest that female capabilities are more important in the age of globalization and continuous changes in the market (Eagly and Sczesny, 2009; Schein, 2007; Schaap et al., 2008).

Effectiveness and decision making are also a major aspect of leadership skills. Female leaders are as successful and effective as their male counterparts (Eagly et al., 1995), even though, they have a different approach to growth strategy. However, according to outcome of some studies, in regard to decision making, which has a critical impact on survival of organizations, gender has a significant direct effect on growth of organizations Davis et al. (2010).

Although researchers have been analyzing the characteristics of effective leaders and the differences between male and female leadership behavior, it is important to review situational leadership theories. According to situational leadership theories, effectiveness of leader behavior depends on the contextual variables, such as the nature of the activities and characteristics of subordinates: "situational contingencies dictate your style for that moment" (Lumsden, \& Wiethoff, 2010, p. 258).

Due to narrow body of research in leadership in Kuwait, an explorative approach is applied. The main focus is on the full range of leadership paradigm (Avolio \& Bass, 1991), distinguishing between transactional, transformational, and laissez-faire leadership styles.

\section{Research methodology}

One of the widely used tool among researchers is Multifactor Leadership Questionnaire (MLQ) and many studies have been carried out with the MLQ (Dumdum, Lowe, \& Avolio, 2002; Judge \& Piccolo, 2004; Lowe,Kroeck, \& Sivasubramaniam,
1996) and have consistently shown that transformational leadership leads to higher subordinate performance and satisfaction levels than transactional leadership. Transactional leaders also produce positive effects on these variables, but such effects are always lower than those achieved by transformational leaders (e.g., Molero, Cuadrado, Navas, \& Morales, 2007). Lastly, laissez-faire is negatively correlated to effectiveness and satisfaction.

The current research study was a quantitative study and assessed leadership style by using the Multifactor Leadership Questionnaire (MLQ) 5X, 2nd Edition. All 45 items were used to collect the data. The scale ranged for 1 (very low) to 5 (very high). Table 1 summarizes transformational, transactional and laissez-fair leadership styles.

Table 1: Summary of transformational, transactional and laissezfair leadership styles reproduced by Eagly, A. H., JohannesenSchmidt, M. C., \& van Engen, M. L. (2003)

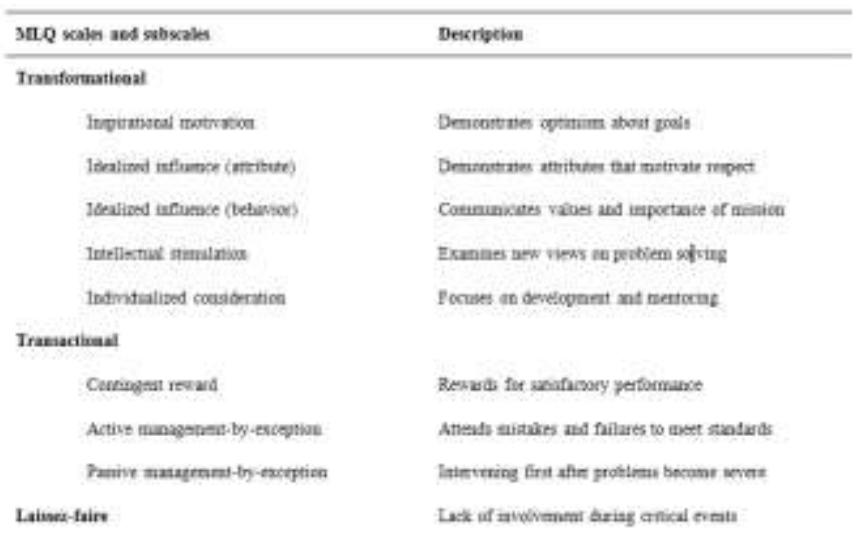

\section{Data collection}

The data collection was conducted in November 2015; 100 questionnaires were distributed to Kuwaiti managers in different industries. Out of 100 distributed questionnaires 62 returned completed resulting in $62 \%$ usable responses. The sampling procedure was simple random sampling and the researcher went to several organizations and respondents to brief on objectives of the study and to give guidelines in answering the questionnaire. The questionnaire was first translated into Arabic by a translator team, reviewed by two subject matter experts and then validated through a pilot test and distributed in both Arabic and English language.

\section{Results}

The purpose of this study was to analyze the difference in leadership style between male and female in Kuwait. There were fewer female respondents $(n=24)$ than male respondents $(n=38)$. All of the survey participants are from Kuwait and from both public and private sector. It should be highlighted that $85 \%$ of Kuwaitis work in public sector. The demographic data is presented in table 2. Most of participants are in the age ranging from 40 to $50(45.1 \%)$, followed by 29 to 39 (30.6\%). $37.1 \%$ of interviewees has 11 to 15 years of experience in leading positions and $33.9 \%$ of them has 6 to $10 ; 27.4 \%$ has 1 to 5 years and only $1.6 \%$ has more than 15 years of work experience in leading positions. 
Table 2: Respondents demographics

\begin{tabular}{|lll|}
\hline Variable & Frequency & Percentage \\
$18-28$ & 3 & $4.9 \%$ \\
$29-39$ & 19 & $30.6 \%$ \\
$40-50$ & 28 & $45.1 \%$ \\
$>50$ & 12 & $19.4 \%$ \\
& & \\
Gender & & \\
Male & 38 & $61.2 \%$ \\
Female & 24 & $38.8 \%$ \\
& & \\
Years of service & & $27.4 \%$ \\
$1-5$ & 17 & $33.9 \%$ \\
$6-10$ & 21 & $37.1 \%$ \\
$11-15$ & 23 & $1.6 \%$ \\
$>15$ & 1 & \\
Level of education & & $4.9 \%$ \\
High School & 3 & $19.4 \%$ \\
Diploma & 12 & $30.6 \%$ \\
Bachelor & 24 & $37.1 \%$ \\
Master & 23 & $0 \%$ \\
PhD & 0 & \\
\hline
\end{tabular}

The scores that male and female managers in Kuwait assigned to themselves are presented in table 3. Female leaders scored higher in Inspirational motivation (M 0.77, F 0.89), intellectual stimulation (M 0.87, F 0.98) and individualized consideration (M 0.79, F 0.83) but scored lower in idealized influence (M 0,81, F 0.76 and M 1.05, F 0.80). Female respondents also scored lower in contingent reward (M 0.91, F 0.83) and active management-by-exception (M 0.8, F 0.69) but higher in passive management-by-exception (M 0.76, F 0.82 ) and surprisingly, female scored also lower in laissezfaire (M 0.84, F 0.81).

Table 3: Summary of managers self-rating in Kuwait

\begin{tabular}{|c|c|c|c|}
\hline Trassformatiseal & Mean & Miedia & SD \\
\hline \multirow[t]{2}{*}{ Inspotrational motruation } & $\mathrm{M} 3.52$ & $\mathrm{M} 4$ & Mon \\
\hline & F 3.69 & $F+$ & $\mathrm{F} 0.89$ \\
\hline \multirow[t]{2}{*}{ Idealized infueace (altribule) } & M 3.58 & $\mathrm{M} 4$ & $\mathrm{M} 0,81$ \\
\hline & F 3.24 & 74 & $\mathrm{~F} 0.76$ \\
\hline \multirow[t]{2}{*}{ Idealized influence (behaviot) } & M 3.23 & M3 & M 1.05 \\
\hline & 73.86 & 84 & $F 0.30$ \\
\hline \multirow[t]{2}{*}{ Inteliectual stimulation } & M 3.50 & $\mathrm{M} a$ & Mo.87 \\
\hline & $F 3.46$ & $F 4$ & Fos \\
\hline \multirow[t]{2}{*}{ Individualined cossidersion } & M 3.51 & $\mathrm{M} 3$ & Mo.79 \\
\hline & F 3.53 & 74 & F 0.83 \\
\hline \multicolumn{4}{|l|}{ Transactional } \\
\hline \multirow[t]{2}{*}{ Confingent teward } & M1 3.54 & $\mathrm{M} 4$ & M09! \\
\hline & F 3.77 & $F_{4}$ & F 0.83 \\
\hline \multirow{2}{*}{$\begin{array}{l}\text { Active mungement by } \\
\text { exception }\end{array}$} & M 3.39 & M3 & Mos \\
\hline & F 3.50 & $F_{4}$ & $F 0.08$ \\
\hline \multirow{2}{*}{$\begin{array}{l}\text { Passive mumagement by. } \\
\text { ecception }\end{array}$} & M 3.7 & $\mathrm{M} 4$ & Mo.76 \\
\hline & $F 3,70$ & $\mathrm{~F} 4$ & F0.82 \\
\hline \multirow[t]{2}{*}{ Laissez-faine } & M 3.53 & $\mathrm{M} 4$ & M0.84 \\
\hline & F 3.58 & $\bar{E}$ & F 0.81 \\
\hline
\end{tabular}

\section{Discussion}

According to the outcomes of this study, male and female leaders use the same behaviors and there are no major differences between male and female leadership style in Kuwait. This result is in opposition to researchers, which have found that men tend to practice transformational leadership and female transactional (Eagly et al., 1992).

Another interesting outcome is that Kuwaiti leaders apply both transformational and transactional leadership approach and the assumption of the author is that they responded to the questionnaire based on contextual situations and do not follow the same leadership style at all times. This is an important topic for further investigation.

\section{Limitations and directions for further research}

This research analyzed Kuwaiti leadership style, however, the contextual issues were not take into consideration. It is essential to apply situational theories and measure the effectiveness of leaders depending on contextual elements. According to situational leadership theories, effectiveness of leader behavior depends on the context.

The majority of work force in Kuwait is non-Kuwaitis; however, most leading positions are assigned to Kuwaitis. It might be interesting to analyze the impact of nationality and culture on leadership style. Further analysis should cover how subordinates and superordinate rate the leadership styles, as the results in this study are limited to self-rating of leaders. This study did not analyze contextual variable such as nature of tasks. It is also important to mention that $85 \%$ of Kuwaitis work in governmental sector, which means future research should be conducted with a fair sampling between private and governmental sector.

\section{Acknowledgement}

This research was supported by Arab Open University (AOU), Kuwait branch. The author thanks AOU Kuwait branch, which greatly assisted the research, although AOU Kuwait branch may not agree with all of the interpretations/conclusions of this paper.

\section{References}

1. Alowaihan, Abdullah Kh. (2004): Gender and business performance of Kuwait small firms: A comparative approach. International Journal of Commerce and Management,14(3/4): 69-82, CrossRef

2. Bass, B. M. (1985): Leadership and performance beyond expectations. New York: Free Press.

3. Bass, B. M. (1990): Bass and Stogdill's handbook of leadership: Theory, research, and managerial applications (3rd ed.). New York: Free Press.

4. Bass, B. M., \& Avolio, B. J. (1990): Transformational leadership development: Manual for the Multifactor Leadership Questionnaire. Palo Alto, CA: Consulting Psychologists Press.

5. Bass, B. M., Avolio, B. J., \& Atwater, L. (1996): The transformational and transactional leadership of men and women. Applied Psychology: An International Review, 45, 5-34, CrossRef

6. Bass, B.M., Avolio, B.J. (2000): Technical Report for the MLQ. Mind Garden, Redwood.

7. Benjamin, L. Flynn, F.J. (2006): Leadership style and regulatory mode: Value from fit?. Organizational Behavior and Human Decision Processes, 100, pp. 216-23, CrossRef

8. Eagly, A. H., Carli, L. L. (2007): Through the labyrinth: The truth about how women become leaders. Boston: Harvard University Business School Press.

9. Eagly, A. H., Johannesen-Schmidt, M. C., van Engen, M. L. (2003): Transformational, transactional, and laissez-faire leadership styles: A meta-analysis comparing women and men. Psychological Bulletin, 129, 569-591, CrossRef

10. Hall, J. A., Carter, J. D. (1999): Gender-stereotype accuracy as an individual difference. Journal of Personality and Social Psychology, 77, 350-359, CrossRef

11. Hilton, J.L. and von Hippel, W. (1996). Stereotypes. Annual Review of Psychology, 47(1):237-271, CrossRef

12. Hoffman, R. M., \& Borders, L. D.(2001). Twenty-five years after the Bem Sex-Role Inventory: A reassessment and new issues regarding classification variability. Measurement and Evaluation in Counseling and Development, 34, 39-55. 
13. Holt, Cheryl L., and Jon B. Ellis. (1998). Assessing the current validity of the Bem Sex-Role Inventory. Sex Roles39(11-12): 929941, CrossRef

14. Javidan, M. and Dale, E.C. (2005) 'Leadership across Cultures: A Study of Canadian and Taiwanese Executives', Management International Review 45(1): 23-44.

15. Kanter, R., 1993. Men and women of the corporation. New York: Basic Books.

16. Katsurada, Emiko, and Yoko Sugihara. "A preliminary validation of the Bem Sex Role Inventory in Japanese culture." Journal of CrossCultural Psychology30, no. 5 (1999): 641-645, CrossRef

17. Kunkel, A.W. and Burleson, B.R., 1999. Assessing Explanations for Sex Differences in Emotional Support A Test of the Different Cultures and Skill Specialization Accounts. Human Communication Research, 25(3):307-340 Lee, Tiane L., and Susan T. Fiske.2006.

18. Lumsden, G., Lumsden, D., \& Wiethoff, C. (2010). Communicating In Groups and Teams: Sharing leadership (5th ed). Boston, MA: Wadsworth Cengage.

19. Metcalfe, B. D. 2007) Gender and human resource management in the Middle East. The International Journal of Human Resource Management, 18(1), 54-74, CrossRef

20. Metcalfe, B. D. 2011. Women, empowerment and development in Arab Gulf States: a critical appraisal of governance, culture and national human resource development (HRD) frameworks. Human Resource Development International, 14(2), 131-148, CrossRef

21. Omair, K. 2010. Typology of career development for Arab women managers in the United Arab Emirates. Career Development International, 15(2), 121-143, CrossRef

22. Powell, G.N., Butterfield, D.A. and Parent, J.D., 2002. Gender and Managerial Stereotypes: Have the Times Changed? Journal of Management, 28(2):177-193, CrossRef

23. Sharoni, Simona. 1997. Women and Gender in Middle East Studies: Trends, Prospects and Challenges.Middle East Report 205: Middle East Studies Networks, pp. 27-29.

24. Scase, R. and Robert Goffee., 1990. Women in management: towards a research agenda. International Journal of Human Resource Management, 1(1): 107-125, CrossRef

25. Schein, Virginia E., Rüdiger Müller, Terri Lituchy, and Jiang Liu. 1996. Think manager - think male: A global phenomenon?Journal of Organizational Behavior 17(1): 33-41, CrossRef, CrossRef

26. Swim, J. K. (1994). Perceived versus meta-analytic effect sizes: An assessment of the accuracy of gender stereotypes. Journal of Personality and Social Psychology, 66, 21-36, CrossRef 